\title{
The power in the interview: A practical guide for identifying the critical role of actor interests in environment research
}

\author{
Ahmad Maryudi ${ }^{1, *}$ and Micah Fisher ${ }^{2}$ \\ 1 Sebijak Institute, Faculty of Forestry, Universitas Gadjah Mada, Indonesia \\ 2 Faculty of Forestry, Universitas Hasanuddin, Indonesia \\ *Correspondence author: ahmad_maryudi@ugm.ac.id
}

\begin{abstract}
In policy discussions of sensitive and complex issues, particularly in the field of forestry and natural resources, interests play an integral role, but are often a challenging component to contextualize, understand, and study. For various reasons related to factors of influence and authority, actors often do not want their interests uncovered by either competitors or even by non-partisan researchers. Nevertheless, identifying such interests continue to be a critical task for the research community, particularly if we are to better understand the broader effects, effectiveness, or shortcomings of policy. In this short policy brief, we provide a practical guide for researchers to capture and incorporate actor interests as part of their empirical evidence through the interview process. Following an empirical-analytical approach, we first distinguish interests of two different types, the formal and informal. Thereafter, our guide lays out an approach consisting of four distinct phases, namely: i) deciding on the interview format, ii) creating situational settings for the interview, iii) preparing interview guides; and iv) triangulating the interview. In each phase, we underline the importance of a culture of generosity and positivity directed toward the interviewees, comfortably engaging them to describe factors and scenarios in rich detail, while also encouraging respondents to express their values and feelings toward both the area of study and other actors across policy networks.

- Actor interests are always a sensitive issue in policies related to the environment, which are often purposefully hidden by actors, and commonly overlooked by research;

- We develop a practical guide based on a set of principles for researchers to use when approaching interviews, which will help to more effectively understand and contextualize actor interests, and can ensure more robust findings about policies related to the environment and natural resources;

- This guide lays out four distinct phases for approaching the complex and sensitive issue of actor interests for data collection using interviews, namely through the way researchers i) structure interview formats, ii) set up situational settings, iii) approach the preparation and delivery of guiding questions, and iv) triangulate the interview.
\end{abstract}

Keywords: critical policy analysis; actor interests; power; qualitative interview; forest policy; forest governance

\begin{tabular}{ll}
\hline Method Descriptions & \\
\hline Specific subject area & Forest policy and governance \\
Method name: & Identification of actor's interests \\
Name and reference of original method & - \\
\hline
\end{tabular}

\section{Introduction}

Actor interests has become one of the fundamental tenets of policy analysis. Krott (2005) goes as far as defining policy making as "a social bargaining process for regulating conflict of interest." Indeed, policy questions are indelibly shaped by who benefits, and who loses. In any public policy, actors engage in contests for shaping policy outcomes. As such, policy actors articulate and define policy priorities based on their interests of formulation, implementation, and evaluation (Aurenhammer, 2016; Fatem et al., 2018). Given the competitiveness and high stakes of policymaking, in which outcomes often guide the allocation of resources, policy actors understandably do not want their interests uncovered by competitors, and will often go to great 
lengths to keep their interests hidden (Krott, 2005). Interests are therefore a sensitive issue in research. As a result, researchers also often make the mistake of overlooking interests or treating them in uncritical ways. Without researchers taking on the critical issue of interests however, the quality of our work will continue to remain stunted for its relevance. Given this context for the overall need to more closely examine interests, doing so is also no easy task, and there has been little in the literature about how to approach the practical elements of identifying interests.

A large collection of policy studies in recent years in the context of the environment has dedicated close attention on actor interests around specific policies or programs (e.g. Burns \& Giessen, 2016; Sahide et al., 2018; Maryudi et al., 2016; Nurrochmat et al., 2018). Nonetheless, though these studies provider critical context and empirical findings about actor interests, they do little to provide us with information about how interests were disclosed during the data collection phases. At best, they acknowledge the potentially hidden interests in politically contested issues, or simply disclose broad strokes about the indicators or measures they undertook for triangulation through general language on common research strategies to calibrate findings. Meanwhile, on the methodological side, scholars (e.g. DiCicco-Bloom \& Crabtree, 2006; Bryman, 2001) have sought to more deliberately suggest procedural approaches. This can be done through document analysis, which must go through a great deal of sleuthing to identify actor interests (Rahayu et al., 2019), carefully parsed through by strategies of critical qualitative research traditions of, for example, discourse analysis (e.g. Gee, 2014). A more efficient approach to identifying the key drivers of interests that shape the enabling policy environment is through the interview. The aforementioned methodological researchers and the guidance they provide, however, do not go into the depth of engaging on general interview procedures, and instead only provide superficial guidelines on the specific topic of approaching the interview as a way for studying actor interests. In this short policy brief, we hone in on the power of the interview as a way to highlight the possibilities for maximizing the interview process in a way that carefully studies actor interests in hopes of helping researchers to conduct more robust methods at researching human-environment relations.

The procedures of revealing hidden interests in the interview process cannot be taken for granted, and requires rigorous preparation, careful approach, and deliberate execution. Although some people have a more natural ability and disposition to project a sense of comfort to a respondent and elicit information about actor interests, there is much to be gained from more closely scrutinizing and engaging on a more deliberate approach to the methodological elements of the interview. Furthermore, in our experience in publishing articles in scientific journals, as reviewers, editors or authors we often question -- or are questioned during the review process -how we came to our conclusions about actor interests. Since policy actors are usually reluctant to share their interests, for researchers justifying a particular finding about actor interests or attesting to the accuracy of their findings, can pose a challenge. Indeed, Berry (2002) highlights the fact that only a few policy scientists have built reputations for interview skills. Without clear protocols and procedures, researchers can risk compromising the overall robustness, validity, and applicability of their studies.

To address the specific task of examining the practical aspects of approaching the interview to identify interests, this short note proceeds as follows. In section two, we describe in simple terms two distinct interests: the formal and informal. In section three we transition to the particulars of the interview, providing guidelines for researchers to more accurately capture the empirical evidence of real interests among policy actors. Overall, with this piece we expect to nudge along efforts at alleviating the [perceived] laden-problems in social science associated with objectivity, measurability, and predictability (see Machlup, 1961), and more explicitly introduce rigor and reliability about social science research approaches and findings. 


\section{Distinguishing formal and informal interests}

Krott (2005: 8) argues that "interests are based on action orientation, adhered to by individuals or groups, and they designate the benefits the individual or group can receive from a certain object." This definition articulates the directions to which actors expect certain policies to move, ordering the trajectories of potential outcomes. Interests are often associated with 'motivation', 'purpose', 'goals' and 'targets' (Hermans \& Thissen, 2009). Interests provide "an explanation for why actors act as they do" (Hindess, 1982: 506). In policy settings rife with conflict -- such as policies related to the environment, natural resources, and forestry -- actors usually disguise their true interests with the more normative statements of intent (Krott, 1990).

Table 1. Differences between formal and informal interests

\begin{tabular}{ll}
\hline Types of interests & Features \\
\hline Formal & - Formally pronounced \\
& - Normatively framed \\
& - Concealing true motives \\
\hline Informal & - True motives \\
& - Hidden \\
& - Reflected by course of actions \\
\hline
\end{tabular}

For instance, Fatem et al. (2018) reveals that conservation narratives are used to camouflage economic gains from forest resources. In studies of bureaucratic politics, particularly those in forestry (Burns et al. 2016; Sahide et al., 2016; Rahman et al. 2017), a bureaucracy agent usually has organizational self-interests of maintaining and increasing its authority, maximizing the use of budgets, and expanding staff recruitment towards those ends. For policy analysis, it is thus important to distinguish the formally announced decisions relative to the intended consequences, versus the real effects that actors genuinely anticipate (Easton, 1965). The hidden agenda is often referred to as the informal interest, reflected by the course of action (Krott, 2005). In an ideal world, actors attempt to achieve formal and informal interests simultaneously. When they conflict with one another, actors tend to prioritize their informal interests (Krott, 2005; Fatem, 2018). As a result, if researchers are unequipped for studying these critical elements, lack the preparation and skill at collecting relevant data on interests, the role that research can play also suffers. Therefore, a tool for data collection like the interview, holds tremendous power and possibility to generate data amidst the normative realms of the formal. It is thus surprising that the art and science of the interview has not received greater attention and scholarship.

\section{Interviewing policy actors, disclosing hidden agendas}

Data collection is an important step in obtaining quality evidence for hypothesis testing or engaging with theory, which eventually leads to making particular conclusions or outcomes about a research topic. Interview has emerged as one of the most widely employed methods in qualitative research (Bryman, 2001), including in forest policy inquiries (Laraswati et al., 2020). The interview is "suitable to the exploration of attitudes, values, beliefs and motives [and] provides the opportunity to evaluate the validity of the answers by observing non-verbal indicators, which is particularly useful when discussing sensitive issues" (Barriball \& While, 1994). However, interviews are complicated, difficult to schedule, execute, pin down, and theorize, and approaches for transcribing often lead to overwhelming decisions on the selection of analytical decision points. In short, throughout the many decisions associated with the interview, analysis can go astray long before ever engaging with the 
data. Daniel and Valencia (1991) show that interviews tend to fail due to the low skills of the interviewer, or due to various variables related to communication barriers, and the limited knowledge of the persons being interviewed.

The issue of interest is also laden with obfuscation and obscurity from the overall subtext of politics, and is a sensitive issue in any case related to policy and its concomitant allocation of resources. Due to these factors, the lack of guiding methods and inadequate preparation by researchers, actors can be reluctant to be mentioned, suffer from interview fatigue, and develop a sense of mistrust towards seemingly objective researchers. Actors that are regularly interviewed also develop clever ways to pivot and redirect, carefully narrating disguised responses to avoid divulging key pieces of information. Interviewers must thus be able to generate honest responses with minimal bias (Qu \& Dumai, 2011), and also must honor the time and willingness of respondents to engage in the act of the interview (Lassiter, 2005). Indeed, the interview should not be seen merely as a condition of data extraction, but also as an event that is potentially worthwhile for the interviewee. Those that are able to secure time with and entice influential decision makers to sit for an interview should not miss such a valuable opportunity to make sense of the trends taking place about a given field but also to engage the interviewee in reflective discussions about the implications of their work. Such reflective and meaningful conversations might have far reaching implications. As such, conducting an interview is no simple enterprise, and we are arguing here that developing the skills of interviewers are a key, yet underappreciated factor. Notwithstanding doing the necessary "homework" to collect as much background information as possible about the overall context of a given issue and the actors involved, we now turn to four key principles that researchers should keep in mind about the power of the interview. We view these four areas as necessary inflection points to consider, which can serve as a practical guide for developing the relevant skills and principles for approaching the interview, and for future improvements.

\subsection{Considering interview formats, their strengths and limitations}

There are different formats and types of interviews, from the structured to the non-structured. Structured interviews offer high research reliability in the form of responses to directed questions, culled from different interviewees that can be aggregated, standardized, and compared (Bryman 2001). Such research continues to hold an important place in policy analysis and by no means are we arguing against such approaches. Nevertheless, an emerging and increasingly rich body of research on critical analysis and power relations show that it is difficult to reveal true interests by only examining the consistent responses aggregated by the more classical quantitative data approaches. The formal interview, particularly when conducted in settings that respondents are disincentivized to reveal their true interests, almost necessarily results in findings that overlook the hidden interests shaping outcomes.

Non-structured Interviews are instead aimed at following a set of principles in order to explore values and motives of certain actors. Such approaches can more flexibly explore meaning and probe in greater depth, examining respondent perceptions toward particular programs, policies, and politics. Non-structured interviews are nevertheless sometimes misjudged as lacking rigor, and indeed, doing them well is methodologically challenging. Furthermore, we have shown that guidelines for preparing and approaching such an interview are few and far between. As a starting principle, the necessary preparation requires developing the depth of understanding about the issue on hand. When skillfully approached, the non-structured interview allows the interviewer to develop, adapt and generate follow-up questions to expand into profound discoveries that uncover new possibilities (Qu \& Dumai, 2011).

There is a catch on the issue of preparation however. This type of non-structured interview "proceeds from the assumption that the interviewers do not know in advance all the necessary questions" (Qu \& Dumai, 2011), requiring the research to also rely on signals, body language, 
instincts, and other overlooked and underappreciated skill sets. Furthermore, such statements are sure to provoke a fundamental and longstanding contradiction among the scientific community, specifically among policy analysis rooted in positivist research paradigms and traditions that suggest research requires a priori hypotheses (Kleinschmit et al., 2016). In this paper, we are not taking a stand of one against the other, and believe in the power of diversity in multiple approaches that utilize structured, non-structured, and semi structured approaches.

Our particular preference in this paper revolves around the semi-structured interview type, which can help to yield multiple benefits. The interviewer in this scenario is guided by a list of general stimulating questions, but which is also provided "some latitude to ask further questions in response to what are seen as significant replies" (Rehmet and Dinnie, 2013: 33). More importantly, the semistructured interview can disclose important and often hidden facets of human and organizational behavior (Qu \& Dumai, 2011), but which maintains the principles of reliability, validity, and opportunities for generalizability that are critical elements of more classical research models. We now turn to the more situational dimensions of the interview setting.

\subsection{The situational setting of the interview}

Creating a positive interview atmosphere is a fundamental and often under-appreciated element, which is often characterized by a "strangeness" of the encounter between the interviewer and interviewee (DiCicco-Bloom and Crabtree 2006). Particularly to individuals that are unknown to each other, much of the early parts of the interview can be relegated to building a sense of trust. If the interview questions are particularly sensitive or pointed, this could affect the willingness of a respondent to divulge information, or the forthrightness in their responses. Therefore, the interviewer is encouraged to shape the situational contexts that make the interviewee feel at ease and unthreatened (Hannabuss, 1996). It is also necessary to establish a safe and comfortable environment for sharing the interviewee's personal experiences and attitudes (DiCicco-Bloom and Crabtree 2006). The positive atmosphere must be maintained to facilitate the continuous flow of the interview.

From our field experience working with public officials, if critical questions begin to suggest the interviewee's involvement or implication of wrongdoing, in which the interviewees begins to be suspicious about the motivations of the research, in which the interviewee begins to feel that the research outcomes will somehow lead to anticipated critique against them, the respondent is likely to provide limited answers. On the other hand, when an official is made to feel that their decisions have far-reaching implications, and the interviewer empathizes with the complexity of the situation, the respondent is much more likely to try to connect, and will likely not require prodding to share their feelings about an important topic and their role in the outcomes of the matter at hand.

On the other hand, meeting people in what we call 'habitats of comfort' is particularly important when working with marginalized groups. Although this is true of the public official that might feel most comfortable at their office workstation or at a local coffee shop, such factors are especially true among marginalized communities. The second author clearly learned this when trying to interview farmers at the local village development halls or conducting FGDs at the homes of local leaders or meeting with them in other official settings (see Scott, 1985 for more on this dynamic). There is no substitute to giving the interviewee a sense of authority by being in their element. With the rice farmer example, they gain strength and authority by being in settings and in conditions where they are speaking on issues they know best. These conversations should therefore begin by talking about the quotidian science of experience embedded in the layered experiences of seasonal tasks such as crop preparation, planting, maintenance, harvest, and repeat. Each individual preference for the most comfortable interview setting may be different, and at times the researchers might not know the preference of their anticipated respondent. Nevertheless, there are ways to anticipate this critical factor prior to engaging in the interview. 


\subsection{Interview guides/questions}

One area of paramount importance is in the preparation of stimulus questions that are effective for disclosing actor interests. Needless to say, the interviewers will obtain few responses if they use the following question: "what is your goals/motives in implementing the [specific policy/program]". Using such a question can instead backfire for its perceived accusational intent. Particularly among individuals with status and a busy schedule, it is no easy task to get such key informants to sit for interviews. Therefore, the opportunity must be maximized through strategic preparation of interview guidelines. Numerous methodological scholars (e.g. Patton 2010; Britten, 1995) argue that for sensitive issues as actor interests, the initial questions should be developed as broad, openended, and neutral, delivered in non-threatening ways to the interviewees despite the a priori hypotheses of the interviewer. One extremely effective way to engage the interviewee is to bring them into the broader "so what" of your research question. Clue them into why it is so important to answer the questions that you are seeking out to answer, and help them to consider how to answer the bigger questions. Furthermore, the act of anticipation in detailing out interview guides provides for ways to consider the most appropriate questions and the many trajectories that might unfold during the interview. In our experience, though the interview guide may hardly be used during the interview, this does not undermine the importance of preparing one.

Following the initial apprehension phase when meeting a respondent for the first time, the interviewer might also start inquiring into general knowledge on the specific policy/program being studied. Although these might seem too general at the outset, it is a safe space to begin to help the setting seem more at ease. Furthermore, the overall characterization about the broader policy issue on hand already provides valuable analytical potential. Such a question as "what is your knowledge on [studied policy/ program]" is helpful for initiating the interview as it is neutral among actors. With this non-threatening question, the respondent may provide important markers about what might potentially be possible as follow up questions. Seasoned researchers that are well-informed about the topic, should already be able to make sense at an early phase of the interview on hints about interests, alliances, and worldviews that will structure follow up questions, giving rise to new possibilities through strategic follow up. Additional questions that might ensue include the following: "What would be an optimal way for implementing the [focal policy/ program]." Although this type of question indicates values and attitudes, it still remains positive and non-directive, and the value of such a question can generate long and detailed responses about the respondent's preferences, which can be probed further through follow up clarifications and additional questions.

Our extensive experience of conducting research in power relations (actors, interests, power) have taught us that with positive and non-directive questions, our interviewees are often encouraged to provide much more detail, helping the interviewer to interject in brief moments of requesting additional clarification and justification. As the interviewee develops confidence in the topic and trust in the process, good interviewers and sound interview structure will help the interviewee feel less apprehensive about divulging interests. Indeed, when it comes to the critical role of interests, the magic of research happens when the interviewee begins to express feelings about the constellations of positions among the various actors involved.

For those that have experienced the emerging magic of the interview scenario, there is a sense about when critical issue of interests begin to crystallize in the interviewee's responses. When these signs appear, the subsequent question is how to continue to cultivate such momentum. When it comes to approaching interviews, there is always the important and unresolved instinctual question about when to allow the interviewee to continue to speak, or whether it is time to probe, follow a tangent, redirect, or at what point it is it time to interject, or end the interview. When examining interests, there is certainly no right or wrong answer. Part of it is in the attentiveness towards the details, observing non-verbal indicators such as the interviewee's gestures and tone. It is not our intent here to describe some secret art, that can holistically encompass its many moving parts, one 
that is necessarily difficult to articulate or pin down. Our view is certainly that such skills can continue to be practiced and honed, which is at the core of what we seek to express in this paper. We now shift our attention to one final element of the interview, which does not only describe how to approach the singular interview, but rather, identifies the equally important question of identifying who should be interviewed in the first place.

\subsection{Triangulation: Finding the "trim tabs"}

Triangulation generally refers to the need to return to the data and scrutinize from new angles and approaches to ensure validity. In our formulation herein, this certainly refers to the data collected of a particular interview. In some interview settings, respondents are simply not forthcoming, or worse still, respondents can purposely mislead and obfuscate. Such interview outcomes on interests are unsurprising when it comes to high stakes issues and interests governing the division and allocation of resources. Triangulation is certainly important for gathering multiple perspectives about interests.

However, we also include an additional notion of triangulation here, namely in order to identify who is best positioned to articulate information about interests. When it comes to high level policy makers, sometimes those that occupy formal positions, they can be new to those settings, or in other instances, they may have limited knowledge about the decisions taking place behind the scenes. Therefore, here we invoke the metaphor from the American designer and writer Buckminster Fuller, in which he referred to the small rudder on a ship or aircraft called the Trim tab. It is a small and outwardly seems a useless object. However, applying the trim tab can have a tremendous impact by creating a low-pressure zone that can shift the direction of a large vessel. In this light, we suggest that triangulation of the interview should seek to identify the trim tabs of policy making, namely the individuals that might be unseen but either see or have the ability to have an outsized role in influencing interests and outcomes. Such individuals do not often have the highest title or seniority, but through triangulation, identifying the wealth of knowledge among such individuals are a treasure trove of data when seeking to understand interests. Given the breadth of knowledge such individuals have, getting them to reveal information also requires care and a measured approach through the various considerations already listed throughout the other sections of this paper. Such individuals that invoke this trim tab metaphor can also tend to be especially reserved and careful, often keenly aware about the dominant information that they possess, as well as the implications of sharing such information about the broader political landscape. Nevertheless, identifying such individuals and getting them to share can serve to elevate research about interests that can also make the role of researchers hold greater weight in providing depth and timeliness of analysis.

\section{Conclusions}

Considering the potentially tricky challenges facing policy researchers in disclosing actor interests, we have presented a simple practical guide based on a set of principles for approaching, preparing for, and conducting interviews. This guide consists of four phases: deciding on interview formats, creating the right situational settings for conducting interviews, adequately and carefully preparing interview guides, and triangulating to secure the right interviews. In each phase, we underline the importance of a culture of generosity, mutual appreciation, and care when approaching the complexity of the interview. We have not only highlighted the power of possibility for data collection in the interview, but the crucial opportunity to be more methodologically attentive about the role of identifying and engaging with power and interests. This simple guideline can help policy scholars in preparing data collection and furthermore, helps guide researchers to obtain the kind of quality empirical data and information that can elevate research across our fields. 
Furthermore, this reflective policy brief and short guide is also intended to spark a catalytic opportunity for improving future research. We hope that the principles we have set forth provide new inroads for identifying the particularities within each principles, and expand beyond them into new and important considerations for data collection on interests. We thus hope that more critical engagement will ensue in order to build more sophisticated guidelines to enrich scientific approaches to uncover the critical element of interest that shape outcomes of socio-environmental relations.

\section{Conflicts of interest}

The authors declare no conflict of interest.

\section{References}

Aurenhammer, P. (2016). Network analysis and actor-centred approach-A critical review. Forest Policy and Economics, 68: 30-28. doi:https://doi.org/10.1016/j.forpol.2014.12.010

Barriball, K.L., While, A. (1994). Collecting data using a semi-structured interview: a discussion paper. Journal of Advanced Nursing, 19 (2): 328-335. doi:https://doi.org/10.1111/j.13652648.1994.tb01088.x

Berry, J.M. (2002). Validity and Reliability Issues in Elite Interviewing. Political Science and Politics, 35 (4): 679-682. doi:https://doi.org/10.1017/S1049096502001166

Britten. N. (1995). Qualitative interviews in medical research. Bmj, 311(6999), 251-253. doi:https://dx.doi.org/10.1136\%2Fbmj.311.6999.251

Bryman. (2001). Social Research Methods. Oxford: Oxford University Press

Burns, S.L., Giessen, L. (2016). Dismantling Comprehensive Forest Bureaucracies: Direct Access, the World Bank, Agricultural Interests, and Neoliberal Administrative Reform of Forest Policy in Argentina. Society and Natural Resources, 29 (4): 493-508. doi:https://doi.org/10.1080/08941920.2015.1089608

Daniel, D., Valencia, S. (1991). Structured interviewing simplified. Public Personnel Management, 20 (2): 127-134. doi:https://doi.org/10.1177\%2F009102609102000202

DiCicco-Bloom, B., Crabtree, B.F. (2006). The qualitative research interview. Medical Education, 40. (4): 314-321. doi:https://doi.org/10.1111/j.1365-2929.2006.02418.x

Easton, D. (1965). A Framework for Political Analysis. Englewood Cliffs, NJ: Prentice-Hall

Fatem, S.M., Awang, S.A., Pudyatmoko, S., Sahide, M. A. K., Pratama, A.A., Maryudi, A. (2018). Camouflaging economic development agendas with forest conservation narratives: A strategy of lower governments for gaining authority in the re-centralising Indonesia. Land use policy, 78: 699-710. doi:https://doi.org/10.1016/j.landusepol.2018.07.018

Gee, J.P. (2014). An Introduction to Discourse Analysis: Theory and Method. Routledge.

Hannabuss, S. (1996). Research interviews. New Library World, 97 (5): 22-30. doi:https://doi.org/10.1108/03074809610122881

Hermans, L.M., Thissen. W.A.H. (2009). Actor analysis methods and their use for public policy analysts. European Journal of Operational Research, 196 (2): 808-818 doi:https://doi.org/10.1016/j.ejor.2008.03.040

Hindess, B. (1982). Power, interests and the outcomes of struggles. Sociology, 16 (4): 498-511. Retrieved March 22, 2020, from www.jstor.org/stable/42852483

Kleinschmit, D., Bocher, M., Giessen. L. (2016). Forest Policy Analysis: Advancing the analytical $\begin{array}{llll}\text { approach. Forest } \quad \text { Policy } & \text { 1-6. }\end{array}$ doi:https://doi.org/10.1016/j.forpol.2016.05.001

Krott, M. (2005). Forest Policy Analysis. Springer Science \& Business Media

Krott, M. 1990. Öffentliche Verwaltung im Umweltschutz: Ergebnisse einer behördenorientierten Policy-Analyse am Beispiel Waldschutz. (Vol. 5). W. Braumüller. 
Laraswati, D., Rahayu, S. Pratama, A.A., Soraya, E., Sahide, M.A.K., Maryudi, A. (2020). Problemmethod fit in forest policy analysis: Empirical pre-orientation for selecting tested or innovative social-qualitative methods. MethodsX. doi:https://doi.org/10.1016/j.mex.2020.100794

Lassiter, L. E. (2005). The Chicago Guide to Collaborative Ethnography. Chicago: University of Chicago Press

Machlup, F. (1961) Are the Social Sciences Really Inferior? Southern Economic Journal, 27 (3):173184. doi: https://doi.org/10.2307/1055084

Maryudi, A., Citraningtyas, E. R., Purwanto, R. H., Sadono, R., Suryanto, P., Riyanto, S., \& Siswoko, B. D. (2016). The emerging power of peasant farmers in the tenurial conflicts over the uses of state forestland in Central Java, Indonesia. Forest Policy and Economics, 67: 70-75. doi:https://doi.org/10.1016/j.forpol.2015.09.005

Nurrochmat, D.R., Nugroho, I.A., Hardjanto, Purwadianto, A., Maryudi, A., Erbaugh, J.T. (2017). Shifting contestation into cooperation: Strategy to incorporate different interest of actors in medicinal plants in Meru Betiri National Park, Indonesia. Forest Policy and Economics, 83: 162168. doi:https://doi.org/10.1016/j.forpol.2017.08.005

Patton, M.Q. (2010). Developmental Evaluation: Applying Complexity Concepts to Enhance Innovation and Use. Guilford Press

Qu, S.Q., Dumay, J. (2011). The qualitative research interview. Qualitative Research in Accounting \& Management, 8 (3): 238-264. doi:https://doi.org/10.1108/11766091111162070

Rahayu, S., Laraswati, D., Pratama, A. A., Permadi, D. B., Sahide, M. A. K., Maryudi, A., (2019). Research trend: Hidden diamonds - The values and risks of online repository documents for forest policy and governance analysis. Forest Policy and Economics, 100, 254-257. doi:https://doi.org/10.1016/j.forpol.2019.01.009

Sahide, M.A.K., Fisher, M.R., Maryudi, A., Dhiaulhaq, A., Wulandari, C., Kim, Y.S., \& Giessen, L. 2018. Deadlock opportunism in contesting conservation areas in Indonesia. Land Use Policy, 77: 412424 doi:https://doi.org/10.1016/j.landusepol.2018.05.020

Scott, J.C. (2008). Weapons of the Weak: Everyday Forms of Peasant Resistance. Yale University Press.

Sahide, M.A.K., Maryudi, A., Supratman, S., Giessen, L. (2016). Is Indonesia utilising its international partners? The driving forces behind Forest Management Units. Forest Policy and Economics, 69: 11-20. doi:https://doi.org/10.1016/j.forpol.2016.04.002 